\title{
A Canonical Correlation Analysis of Sectoral Composition of GDP and Development in Asia
}

\author{
C. M. Jayadevan \\ Swinburne University of Technology, Melbourne, Australia \\ Email:jdevcm@outlook.com
}

How to cite this paper: Jayadevan, C.M. (2018) A Canonical Correlation Analysis of Sectoral Composition of GDP and Development in Asia. Modern Economy, 9, 379-392.

https://doi.org/10.4236/me.2018.92024

Received: January 17, 2018

Accepted: February 25, 2018

Published: February 28, 2018

Copyright $\odot 2018$ by author and Scientific Research Publishing Inc. This work is licensed under the Creative Commons Attribution International License (CC BY 4.0).

http://creativecommons.org/licenses/by/4.0/

\section{(c) (i) Open Access}

\begin{abstract}
This paper identifies the factors that influence percentage contribution of sectors to gross domestic product (GDP) for a group of 32 Asian countries for two cross-section points 1994-96 and 2014-16. Development theories hypothesize that the percentage share of sectors to GDP undergoes transformation with the level of economic development of the country and the degree of competitiveness of its agricultural sector. This paper employed the use of a canonical correlation analysis for 32 Asian countries. This analysis shows that the structural changes in sectoral GDP composition in the selected Asian countries were significantly determined by the factors like employee productivity, employment growth in services sector, rising life expectancy, growth of value added in manufacturing and gross capital formation.
\end{abstract}

\section{Keywords \\ GDP, Agriculture, Industry, Services, Development}

\section{Introduction}

Economic development and structural changes in GDP are inter-related. We can see a number of studies related to how the agricultural development is determined by various factors like rural population, life expectancy, foreign direct investment, level of agricultural exports etc. There are studies explaining the growth of service sector in terms of urbanization and per capita income. Similarly, growth of industrial sector is explained in terms of capital formation, foreign direct investment, exports etc. Separate studies on agriculture or industry or services sector are based mainly on multiple regression analysis and excluded the effects of development indicators on the structural changes in the composition of GDP. So this study is based on canonical correlation analysis which is a generalization of multiple regression. In this paper, three response variables are con- 
sidered simultaneously instead of a single response variable as in multiple regression analysis.

This paper has selected 32 countries which are major countries in terms of population in Asia. Selected countries on the basis of availability of data are Afghanistan, Armenia, Azerbaijan, Bangladesh, Bhutan, Brunei, Cambodia, China, Georgia, Hong Kong, Iran, India, Indonesia, Japan, Kazakhstan, Korea, Rep., Kyrgyz, Malaysia, Maldives, Mongolia, Myamar, Nepal, Pakistan, Philippines, Russia, Singapore, Sri Lanka, Tajikistan, Thailand, Turkey, Turkmenistan, Uzbekistan and Vietnam.

The study has been confined to two cross-section points, 1994-96 and 2014-16. The main reason for this choice is due to missing data for a number of years. There were no data for Afghanistan, Hong Kong, Maldives and Myanmar for the period 1994-96, so these countries are excluded from the analysis of initial period 1994-96. Data for all 32 countries were available for the period 2014-16.

This paper is concerned with an analysis of how the structural changes in sectoral GDP composition are determined by the indicators of development in the context of a group of 32 Asian countries for two cross-section periods 1994-96 and 2014-16. How the variations in development indicators cause variation in sectoral composition of GDP? This question is answered with the help of canonical correlation analysis between the sectoral composition of GDP and the development indicators of 32 Asian countries for two cross-section periods, 1994-96 and 2014-16.

\section{Literature Review}

In the economic literature there are two main schools of thought on how sectoral composition and growth interrelate. The neoclassical view holds that sectoral composition is a relatively unimportant byproduct of growth. However, scholars associated with the world bank, including Kuznets [1], Rostow [2], Chenery and syrquin [3], and Baumol et al. [4] posit that growth is brought about by changes in sectoral composition [5].

Lewis theory [6] of economic development explains economic development in terms of structural-change which explains the mechanism of changing structure of underdeveloped economies from subsistence agriculture to more modern and more urbanized. Dual sector theory of Lewis emphasized the importance of agricultural sector in the economy as economic growth progresses. In this theory, industrial sector utilizes the surplus labour in the agricultural sector as its source of growth, along with capital generated by the investment of savings, to expand its production and thus gross output of the economy. As the industrial sector expands in importance, there is a concomitant reduction in the percentage contribution to gross domestic product by the agricultural sector. This growth process thus generally requires the movement of labour from rural areas to the urban areas with a decline of the rural population as a percentage of national population [7] [8].

While recognizing that industrialization is necessary condition for economic 
development, there are differing views on sequencing of growth in various sectors. Kaldor, has emphasized that the industrial growth leads to the overall growth. He found a positive correlation between the rates of growth of GDP and the rates of growth of manufacturing output in his study of 12 industrially advanced countries during the period 1953-54 to 1963-64. He observed that the rates of economic growth are almost invariably associated with the fast rate of growth of the secondary sector, mainly, manufacturing [9]. This phenomenon has been so striking to induce some economists to hypothesize that the manufacturing sector is the engine of economic growth, the so-called "engine of growth argument" [9] [10]. Successful industrialization is one aspect of effective development [11].

Wu's study [12] shows that the main determinants of demand for services in India and china are per capita income and urbanization. It is argued that growth of the service sector is determined by several factors such as production specialization, income level and urbanization [13] [14]. These factors are interrelated. As an economy grows, productive activities become more specialized and urbanization accelerates due to the rising level of income. In the meantime, as a result of the increasing specialization of production, firms tend to outsource many service activities such as legal, accounting and security services. Some authors call this process the specialization splintering [15]. It is the main source of demand for services from the producers.

\section{Materials and Methods}

The main source of data for this study is taken from online statistical database published by United Nations ESCAP and World Bank. In this paper we will use a canonical correlation analysis (CCA) as a technique for determining if there is a relationship between two sets of variables, one measuring sectoral GDP composition and the other measuring development. CCA is a multivariate analysis of correlation between two sets of variables. In CCA, we study interrelationships between sets of multiple predictor variables and multiple response variables.

In a multiple regression analysis, a single variable $\mathrm{Y}$ is related to two or more variables $\mathrm{X} 1, \mathrm{X} 2, \cdots \mathrm{Xn}$ to see how $\mathrm{Y}$ is related to the $\mathrm{X}$ variables. From this point of view, canonical correlation analysis is a generalization of multiple regression in which Y variables are simultaneously related to several $\mathrm{X}$ variables [16]. In this paper, CCA is applied because the analysis is carried out not on a single response variable, rather 3 multiple response variables.

Hypothesis of interest is change in development indicators cause change in structure of sectoral GDP composition. The null hypothesis is equivalent to testing the hypothesis that all $\mathrm{p}$ canonical variate pairs are uncorrelated, or the hypothesis of interest is: Ho: $\rho * 1=\rho * 2=\cdots=\rho * \mathrm{p}=0$; Ha: Not all pi equal zero.

Response variables (set 2) representing structure of sectoral GDP composition are: 1) agri_vad, value added from agriculture as $\%$ of gdp, 2) ind_vad, value added from industry as \% of gdp and 3) serv_vad, value added from services, 
etc., as \% of gdp. Three main components of GDP structure are value added from agriculture, value added from industry and value added from services.

Predictor variables (set 1) representing development are: 1) exp, exports of goods and services as \% of gdp, 2) fdi, foreign direct investment, net inflows as $\%$ of gdp, 3) gcf, gross capital formation as \% of gdp, 4) man_vad, value added from manufacturing as \% of gdp, 5) emp_prod, gdp per person employed (constant 2011 PPP \$), 6) life_ex, life expectancy at birth, total, in years, 7) upp, urban population as $\%$ of total, 8) hepu, public health expenditure as \% of gdp, 9) ind_emp, employment in industry as \% of total employment and 10) serv_emp, employment in services as \% of total employment.

Multivariate normality for data sets was conducted using Mardia's and Royston's multivariate normality test. In order to achieve multivariate normality for the response variables, different data transformations had been performed. However, logarithmic transformation was suitable in this case. Variable names are prefixed with 1 indicating it is in logarithm.

\section{Empirical Results}

Summary Statistics for a group of 29 Asian countries for the period 1994-96 is reported in Table 1. Average share of agriculture in GDP was $23.17 \%$, with a minimum $0.17 \%$ and maximum $50.72 \%$. Average share of industry in GDP was $33.92 \%$, with a minimum $15.06 \%$ and maximum $59.37 \%$. Average share of services in GDP was $42.91 \%$, with a minimum $19.13 \%$ and maximum $66.19 \%$. The highest coefficient of variation is observed for the share of agriculture in GDP (61.68\%) followed by the share of industry (29.37\%) and the least for the services (25.53\%) for 1994-96.

Summary Statistics for a group of 32 Asian countries for the period 2014-16 is reported in Table 1. Average share of agriculture in GDP was $12.73 \%$, with a minimum $0.04 \%$ and maximum $33.26 \%$. Average share of industry in GDP was $32.65 \%$, with a minimum $7.2 \%$ and maximum $62.12 \%$. Average share of services in GDP was $54.62 \%$, with a minimum $28.54 \%$ and maximum $92.73 \%$. The highest

Table 1. Summary statistics of percentage sectoral share of GDP in Asia.

\begin{tabular}{ccccccc}
\hline & \multicolumn{2}{c}{ Agriculture } & \multicolumn{2}{c}{ Industry } & \multicolumn{2}{c}{ Services } \\
\cline { 2 - 7 } & $\mathbf{1 9 9 4 - 9 6}$ & $\mathbf{2 0 1 4 - 1 6}$ & $\mathbf{1 9 9 4 - 9 6}$ & $\mathbf{2 0 1 4 - 1 6}$ & $\mathbf{1 9 9 4 - 9 6}$ & $\mathbf{2 0 1 4 - 1 6}$ \\
\hline Mean & 23.17 & 12.73 & 33.92 & 32.65 & 42.91 & 54.62 \\
Median & 21.51 & 10.40 & 33.63 & 32.14 & 42.07 & 54.39 \\
Maximum & 50.72 & 33.26 & 59.37 & 62.12 & 66.19 & 92.73 \\
Minimum & 0.17 & 0.04 & 15.06 & 7.20 & 19.13 & 28.54 \\
Std. Dev. & 14.29 & 8.99 & 9.96 & 11.84 & 10.96 & 13.34 \\
Skewness & 0.19 & 0.51 & 0.44 & 0.41 & 0.05 & 0.74 \\
Kurtosis & -0.75 & 2.40 & 0.85 & 3.93 & -0.13 & 4.00 \\
C.V. & 61.68 & 70.60 & 29.37 & 36.30 & 25.53 & 24.40 \\
\hline
\end{tabular}


coefficient of variation is observed for the share of agriculture in GDP (70.60\%) followed by the share of industry $(29.37 \%)$ and the least for the services (24.40\%).

It is notable that the average share of agriculture in GDP has declined from $23.17 \%$ in $1994-96$ to $12.73 \%$ in $2014-16$. The average share of industry has decreased slightly from $33.92 \%$ in $1994-96$ to $32.65 \%$. On the other hand, the average share of services increased from $42.91 \%$ in $1994-95$ to $54.62 \%$ in $2014-16$ (Table 1).

The percentage share of agriculture in GDP is observed higher for Nepal (33.26), Cambodia (28.74), Myanmar (27.59), Tajikistan (25.72), Pakistan (24.85) and Afghanistan (22.26). The percentage share of agriculture in GDP is found to be less than $1 \%$ for Singapore and Hong Kong and approximately $1 \%$ for Brunei and Japan, less than 3\% for Korea Republic. The percentage share of non-agricultural sector in GDP is the lowest for Nepal, Cambodia, Myanmar, Tajikistan, Pakistan and Afghanistan. On the other hand, the share of non-agricultural sector in GDP is above 95\% for Singapore, Hong Kong, Brunei, Japan, Korea Republic, Russia and Kazakistan (Figure 1).

The correlation between the variables of sectoral GDP share are moderate, the largest being 0.69 between the share of industrial sector and the share of services sector during 2014-16. Similarly, the correlation between the share of agriculture and the share of services are negative for both periods (Table 2).

Some of the correlations between the development variables are high. High correlations are observed between employee productivity and life expectancy, urban population and employee productivity, urban population and life expectancy, employment in services and employee productivity, and foreign direct investment and the level of exports (Table 3). This is true for both periods.

Generally, the correlations between the variables of sectoral share of GDP and development variables are moderate. The share of agriculture has high negative

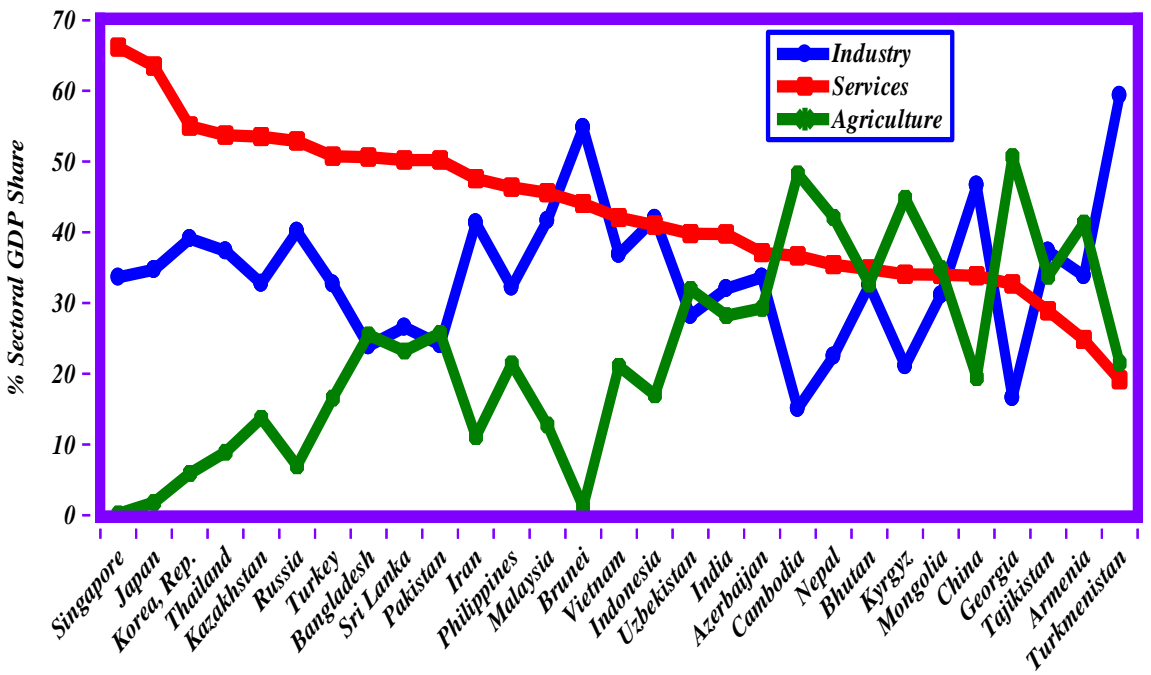

Figure 1. Percentage sectoral share of GDP in Asia during 2014-16. 
Table 2. Correlations among the response variables.

\begin{tabular}{ccccccc}
\hline Year & \multicolumn{3}{c}{$1994-96$} & & $2014-16$ \\
\hline Variable & lagri_vad & lind_vad & lserv_vad & lagri_vad & lind_vad & lserv_vad \\
\hline lagri_vad & 1.00 & & & 1.00 & & \\
lind_vad & -0.43 & 1.00 & & -0.14 & 1.00 & \\
lserv_vad & -0.61 & -0.04 & 1.00 & -0.35 & -0.69 & 1.00 \\
\hline
\end{tabular}

Table 3. Correlations among the development variables.

\begin{tabular}{|c|c|c|c|c|c|c|c|c|c|c|}
\hline & lexp & lfdi & $\operatorname{lgcf} 1$ & man_vad & mp_prod & llife_ex & lupp & lhepu & nd_emp & lser_emp \\
\hline \multicolumn{11}{|l|}{$1994-96$} \\
\hline lexp & 1.00 & & & & & & & & & \\
\hline lfdi & 0.57 & 1.00 & & & & & & & & \\
\hline $\operatorname{lgcf}$ & 0.29 & -0.15 & 1.00 & & & & & & & \\
\hline lman_vad & 0.18 & 0.10 & 0.53 & 1.00 & & & & & & \\
\hline lemp_prod & 0.31 & -0.23 & 0.45 & 0.29 & 1.00 & & & & & \\
\hline llife_ex & 0.21 & 0.01 & 0.24 & 0.46 & 0.62 & 1.00 & & & & \\
\hline lupp & 0.28 & 0.02 & 0.11 & 0.43 & 0.74 & 0.63 & 1.00 & & & \\
\hline lhepu & 0.03 & -0.21 & 0.29 & -0.02 & 0.30 & 0.13 & 0.27 & 1.00 & & \\
\hline lind_emp & 0.27 & -0.13 & 0.56 & 0.71 & 0.72 & 0.61 & 0.68 & 0.23 & 1.00 & \\
\hline lser_emp & 0.27 & -0.10 & 0.22 & 0.26 & 0.85 & 0.64 & 0.87 & 0.32 & 0.71 & 1.00 \\
\hline \multicolumn{11}{|l|}{$2014-16$} \\
\hline lexp & 1.00 & & & & & & & & & \\
\hline lfdi & 0.64 & 1.00 & & & & & & & & \\
\hline $\operatorname{lgcf}$ & 0.22 & 0.06 & 1.00 & & & & & & & \\
\hline lman_vad & 0.03 & -0.15 & 0.08 & 1.00 & & & & & & \\
\hline lemp_prod & 0.44 & 0.05 & 0.09 & 0.24 & 1.00 & & & & & \\
\hline llife_ex & 0.47 & 0.02 & 0.08 & 0.15 & 0.65 & 1.00 & & & & \\
\hline lupp & 0.39 & 0.09 & -0.01 & 0.24 & 0.84 & 0.61 & 1.00 & & & \\
\hline lhepu & 0.21 & -0.12 & -0.03 & -0.10 & 0.38 & 0.58 & 0.40 & 1.00 & & \\
\hline lind_emp & 0.28 & 0.11 & 0.09 & 0.42 & 0.50 & 0.35 & 0.39 & 0.28 & 1.00 & \\
\hline lser_emp & 0.53 & 0.25 & -0.07 & 0.17 & 0.84 & 0.64 & 0.80 & 0.45 & 0.48 & 1.00 \\
\hline
\end{tabular}

correlations with employee productivity, life expectancy and urban population for both periods. The share of industry has moderate positive correlation with manufacturing and employee productivity in both periods. However, the share industry had high correlation with gross capita formation in 1994-96. The share of services had moderate positive correlation with life expectancy for both periods (Table 4).

Four multivariate criteria and the $\mathrm{F}$ approximations for multivariate test of dimension statistics are presented in Table 5. By far the most common method used is Wilk's lamda $(\lambda)$ as it tends to have the most general applicability. In our example, the model was statistically significant, with a Wilk's lamda of $0.03, \mathrm{~F}=$ 
Table 4. Correlations between response variables and predictor variables.

\begin{tabular}{ccccccccccc}
\hline 1994-96 & lexp & lfdi & lgcf & lman_vad & lemp_prod & llife_ex & lupp & lhepu & lind_emp & lser_emp \\
\hline lagri_vad & -0.35 & 0.12 & -0.43 & -0.31 & -0.82 & -0.67 & -0.59 & -0.23 & -0.55 & -0.69 \\
lind_vad & 0.30 & -0.04 & 0.81 & 0.62 & 0.55 & 0.40 & 0.42 & 0.27 & 0.72 & 0.43 \\
lserv_vad & -0.16 & -0.31 & 0.11 & 0.01 & 0.54 & 0.43 & 0.26 & 0.12 & 0.20 & 0.46 \\
2014-16 & & & & & & & & & & \\
lagri_vad & -0.50 & -0.15 & -0.03 & -0.17 & -0.80 & -0.71 & -0.68 & -0.33 & -0.20 & -0.74 \\
lind_vad & 0.20 & 0.06 & 0.36 & 0.52 & 0.43 & 0.06 & 0.35 & -0.14 & 0.28 & 0.25 \\
lserv_vad & -0.02 & -0.06 & -0.37 & -0.14 & 0.15 & 0.42 & 0.21 & 0.43 & 0.02 & 0.33 \\
\hline
\end{tabular}

Table 5. Multivariate statistics and F approximations.

\begin{tabular}{|c|c|c|c|c|c|c|c|c|c|c|}
\hline & \multicolumn{5}{|c|}{$1994-96$} & \multicolumn{5}{|c|}{ 2014-16 } \\
\hline & \multicolumn{2}{|c|}{$S=3$} & \multicolumn{2}{|c|}{$\mathbf{M}=3$} & \multirow{2}{*}{$\begin{array}{c}\mathrm{N}=6.5 \\
\mathrm{Pr}>\mathrm{F}\end{array}$} & \multicolumn{2}{|c|}{$S=3$} & \multicolumn{2}{|c|}{$M=3$} & \multirow{2}{*}{$\begin{array}{l}\mathrm{N}=7 \\
\mathrm{Pr}>\mathrm{F}\end{array}$} \\
\hline & Value & F Value & Num DF & Den DF & & Value & F Value & Num DF & Den DF & \\
\hline Wilks' Lambda & 0.03 & 3.73 & 30 & 44.70 & $<0.0001$ & 0.03 & 3.78 & 30 & 47.64 & $<0.0001$ \\
\hline Pillai's Trace & 1.85 & 2.73 & 30 & 51 & 0.0008 & 1.74 & 2.49 & 30 & 54 & 0.0017 \\
\hline Hotelling-Lawley Trace & 11.49 & 5.38 & 30 & 27.02 & $<0.0001$ & 12.62 & 6.32 & 30 & 29.26 & $<0.0001$ \\
\hline Roy's Greatest Root & 9.53 & 16.19 & 10 & 17 & $<0.0001$ & 11.18 & 20.13 & 10 & 18 & $<0.0001$ \\
\hline
\end{tabular}

$3.73, \mathrm{df}=(30,44.70)$ and $\mathrm{p}<0.0001$ for $1994-96$. On the basis of this, we can reject the null hypothesis that there was no relationship between the variable sets and conclude that there probably was a relationship. Using Wilk's lamda, $1-\lambda=$ $1-0.03=0.97=r^{2}$ for the model. All other test statistics are also significant. This means that the model is significant. This is true for both periods.

Now that we have tested the hypothesis of independence and have rejected them, the next step is to obtain estimates of canonical correlation. The estimated canonical correlations are reported in Table 6 . In general, the number of canonical dimensions is equal to the number of variables in the smaller set; however, the number of significant dimensions may be even smaller. In this example there are three canonical dimensions of which all of them are not statistically significant. For example for 2014-16, the first test of dimensions tests whether all three dimensions are significant $(\mathrm{F}=3.78)$, the next test tests whether dimensions 2 and 3 are significant $(F=1.34)$. The last test tests whether dimension 3 , by itself, is significant $(\mathrm{F}=1.21)$. These results show that only the first canonical correlation is statistically significant. The last two canonical correlations are not significant. The squared values of the canonical variate pairs, found in the squared canonical correlation column, can be interpreted much in the same way as $r^{2}$ values are interpreted. We see that $92 \%$ of the variation in $V_{1}$ is explained by the variation in $W_{1}$. Only the first canonical correlation is very important. This is also true for $1994-96$ where $90 \%$ of the variation in $V_{1}$ is explained by the variation in $\mathrm{W}_{1}$ (Table 6).

Canonical coefficients are shown in Table 7 and Table 8. The raw canonical 
Table 6. Canonical correlations.

(a)

\begin{tabular}{|c|c|c|c|c|c|c|c|c|}
\hline & \multirow{2}{*}{$\begin{array}{l}\text { Canonical } \\
\text { Correlation }\end{array}$} & \multirow{2}{*}{$\begin{array}{l}\text { Adjusted } \\
\text { Canonical } \\
\text { Correlation }\end{array}$} & \multirow{2}{*}{$\begin{array}{l}\text { Approximate } \\
\text { Standard } \\
\text { Error }\end{array}$} & \multirow{2}{*}{$\begin{array}{c}\text { Squared } \\
\text { Canonical } \\
\text { Correlation }\end{array}$} & \multicolumn{4}{|c|}{ Eigenvalues of Inv $€^{*} H=$ CanRsq $/(1-$ CanRsq $)$} \\
\hline & & & & & Eigenvalue & Difference & Proportion & Cumulative \\
\hline \multicolumn{9}{|c|}{$1994-96$} \\
\hline 1 & 0.95 & 0.93 & 0.02 & 0.90 & 9.53 & 8.12 & 0.83 & 0.83 \\
\hline 2 & 0.76 & 0.67 & 0.08 & 0.58 & 1.40 & 0.84 & 0.12 & 0.95 \\
\hline 3 & 0.60 & 0.50 & 0.12 & 0.36 & 0.56 & & 0.05 & 1.00 \\
\hline \multicolumn{9}{|c|}{ 2014-16 } \\
\hline 1 & 0.95 & 0.94 & 0.02 & 0.92 & 11.18 & 10.28 & 0.89 & 0.88 \\
\hline 2 & 0.69 & 0.53 & 0.10 & 0.47 & 0.90 & 0.36 & 0.07 & 0.96 \\
\hline 3 & 0.59 & 0.52 & 0.12 & 0.35 & 0.54 & & 0.04 & 1.00 \\
\hline
\end{tabular}

(b)

\begin{tabular}{|c|c|c|c|c|c|}
\hline & \multicolumn{5}{|c|}{ Test of H0: The canonical correlations in the current row and all that follow are zero } \\
\hline & Likelihood Ratio & Approximate F Value & Num DF & Den DF & $\operatorname{Pr}>\mathrm{F}$ \\
\hline \multicolumn{6}{|c|}{$1994-96$} \\
\hline & 0.03 & 3.73 & 30 & 44.70 & $<0.0001$ \\
\hline & 0.27 & 1.67 & 18 & 32 & 0.1007 \\
\hline & 0.64 & 1.20 & 8 & 17 & 0.3574 \\
\hline \multicolumn{6}{|c|}{ 2014-16 } \\
\hline 1 & 0.03 & 3.78 & 30 & 47.64 & $<0.0001$ \\
\hline 2 & 0.34 & 1.34 & 18 & 34 & 0.2236 \\
\hline 3 & 0.65 & 1.21 & 8 & 18 & 0.3458 \\
\hline
\end{tabular}

Table 7. Canonical coefficients for the sectoral GDP share variables.

\begin{tabular}{|c|c|c|c|c|c|c|}
\hline \multirow[b]{2}{*}{$1994-96$} & \multicolumn{3}{|c|}{ Raw } & \multicolumn{3}{|c|}{ Standardized } \\
\hline & V1 & $\mathrm{V} 2$ & V3 & $\mathrm{V} 1$ & $\mathrm{~V} 2$ & V3 \\
\hline lagri_vad & -0.29 & 0.40 & 1.11 & -0.37 & 0.50 & 1.4 \\
\hline lind_vad & 2.18 & 2.37 & 2.13 & 0.69 & 0.75 & 0.67 \\
\hline lserv_vad & 0.94 & -1.62 & 4.58 & 0.26 & -0.45 & 1.28 \\
\hline \multicolumn{7}{|l|}{$2014-16$} \\
\hline lagri_vad & -0.47 & -0.04 & 0.84 & -0.63 & -0.06 & 1.13 \\
\hline lind_vad & 1.94 & 0.55 & 4.02 & 0.72 & 0.20 & 1.48 \\
\hline lserv_vad & 2.00 & -3.87 & 6.56 & 0.45 & -0.86 & 1.46 \\
\hline
\end{tabular}

coefficients can be interpreted as same as to interpreting regression coefficients. For example, for 2014-16, for the variable employee productivity, 1 percent increase in employee productivity leads to 0.80 percent increase in the first canonical variate of set 2 when all of the other variables are held constant. Similarly, for 2014-16, for life expectancy, 1 percent increase in life expectancy leads to 2.96 percent increase in the first canonical variate of set 2 when all of the other 
Table 8. Canonical coefficients for the development measurements.

\begin{tabular}{|c|c|c|c|c|c|c|}
\hline \multirow[b]{2}{*}{$1994-96$} & \multicolumn{2}{|c|}{ Raw } & \multicolumn{4}{|c|}{ Standardized } \\
\hline & W1 & W2 & W3 & W1 & W2 & W3 \\
\hline lexp & -0.17 & -0.09 & -1.79 & -0.11 & -0.06 & -1.16 \\
\hline lfdi & 0.04 & 0.10 & 0.20 & 0.07 & 0.20 & 0.39 \\
\hline $\operatorname{lgcf}$ & 1.46 & 2.61 & 0.76 & 0.54 & 0.96 & 0.28 \\
\hline lman_vad & 0.41 & -1.81 & 0.56 & 0.15 & -0.67 & 0.21 \\
\hline lemp_prod & 0.45 & -1.11 & 0.21 & 0.51 & -1.25 & 0.23 \\
\hline llife_ex & 1.88 & -3.57 & -2.58 & 0.17 & -0.32 & -0.23 \\
\hline lupp & 0.03 & 2.06 & -1.51 & 0.02 & 1.13 & -0.83 \\
\hline lhepu & -0.02 & -0.23 & 0.05 & -0.01 & -0.12 & 0.02 \\
\hline lind_emp & -0.30 & 1.96 & 0.04 & -0.16 & 1.07 & 0.02 \\
\hline lser_emp & 0.36 & -1.82 & 1.76 & 0.15 & -0.74 & 0.72 \\
\hline \multicolumn{7}{|l|}{ 2014-16 } \\
\hline lexp & -0.08 & 0.57 & -0.94 & -0.06 & 0.43 & -0.71 \\
\hline lfdi & 0.13 & -0.05 & 0.11 & 0.15 & -0.06 & 0.13 \\
\hline $\operatorname{lgcf}$ & 0.21 & 1.42 & 0.49 & 0.06 & 0.40 & 0.14 \\
\hline lman_vad & 0.68 & 0.50 & 1.165 & 0.37 & 0.27 & 0.63 \\
\hline lemp_prod & 0.80 & 0.75 & -0.80 & 0.76 & 0.71 & -0.76 \\
\hline llife_ex & 2.96 & -10.99 & -4.35 & 0.19 & -0.72 & -0.29 \\
\hline lupp & -0.20 & 0.24 & 0.70 & -0.10 & 0.11 & 0.33 \\
\hline lhepu & 0.02 & -0.39 & 0.53 & 0.01 & -0.23 & 0.31 \\
\hline lind_emp & -0.97 & 0.12 & 0.86 & -0.34 & 0.04 & 0.30 \\
\hline 1ser_emp & 0.67 & -1.83 & 1.57 & 0.24 & -0.65 & 0.56 \\
\hline
\end{tabular}

variables are held constant (Table 8). Similarly, high positive raw coefficients are observed for share of manufacturing in gdp (0.68) and employment in services for 2014-16. High negative raw coefficient is also observed for industrial employment (Table 8).

However, for 1994-96, gross capital formation and life expectancy emerged to be significant positive determinants of structural change in GDP. Growth of manufacturing, employee productivity and employment in services were also significant determinants of structural change in GDP for 1994-96. For 2014-16, life expectancy, employee productivity, value added in manufacturing, employment in services and gross capital formation were significant positive determinants of structural change in GDP. However, for 2014-16, the impact of growth of industrial employment was negative on structural change in GDP share. This is also evident from standardized coefficients (Table 8).

The standardized canonical coefficients are reported in Table 7 and Table 8. The standardized coefficients allow for easier comparisons among the variables when the variables in the model have very different standard deviations. The standardized canonical coefficients are interpreted in a manner as same as to in- 
terpreting standardized regression coefficients. For example, consider the variable, the employee productivity, one standard deviation increase in employee productivity leads to 0.76 standard deviation increase in the score on the first canonical variate for set 2 when the other variables in the model are held constant for 2014-16. Similarly, for the variable the share of manufacturing in gdp, one standard deviation increase in the share of manufacturing in gdp leads to 0.37 percent increase in the score on the first canonical variate for set 2 when the other variables in the model are held constant (Table 8).

Below are correlations between observed variables and canonical variables which are known as the canonical loadings, which SAS labels as canonical structure. Correlation between the share of agriculture in GDP and their first canonical variable is negative. Similarly, the correlation between the share of industry in GDP and their first canonical variable is positive (Table 9) which is true for both periods. Similar picture can also be drawn from correlations between the sectoral GDP share and the canonical variables of the development measurements (Table 9).

Correlations between the development measurements and the canonical variables of sectoral GDP share are reported in Table 10. Correlation of first canonical variable with employee productivity, urban population, life expectancy, share of employment in service sector, level of export and share of manufacturing in gdp are high and positive for both periods. Similar picture can also be seen in case of correlations between the development measurements and their canonical variables (Table 10 ).

Royston's multivariate normality test for response data sets fulfilled for the period 2014-16, Mardia's and Royston's multivariate normality test fulfilled for the period 1994-96.

Univariate regression analysis has also been carried out to confirm the results from CCA. The percentage share of value added in agriculture was explained negatively by employee productivity and life expectancy for both periods. This model could explain 67 percent variation in the share of agriculture in GDP (Table 11).

Table 9. Correlations.

\begin{tabular}{ccccccc}
\hline \multicolumn{3}{c}{$\begin{array}{c}\text { Between the Sectoral GDP Share and } \\
\text { Their Canonical Variables }\end{array}$} & \multicolumn{3}{c}{$\begin{array}{c}\text { Between the Sectoral GDP Share and the } \\
\text { Canonical }\end{array}$} \\
\multicolumn{2}{c}{} & & & \multicolumn{3}{c}{$\begin{array}{c}\text { Variables of the Development } \\
\text { Measurements }\end{array}$} \\
\hline 1994-96 & V1 & V2 & V3 & W1 & W2 & W3 \\
\hline lagri_vad & -0.82 & 0.46 & 0.33 & -0.78 & 0.35 & 0.20 \\
lind_vad & 0.83 & 0.55 & 0.02 & 0.79 & 0.42 & 0.01 \\
lserv_vad & 0.46 & -0.79 & 0.40 & 0.44 & -0.60 & 0.24 \\
2014-16 & & & & & & 0.15 \\
lagri_vad & -0.89 & 0.22 & 0.40 & -0.85 & 0.15 & 0.24 \\
lind_vad & 0.50 & 0.80 & 0.32 & 0.48 & 0.55 & 0.20 \\
lserv_vad & 0.18 & -0.98 & 0.05 & 0.17 & -0.68 & 0.03 \\
\hline
\end{tabular}


Table 10. Correlations.

\begin{tabular}{ccccccc}
\hline & \multicolumn{3}{c}{$\begin{array}{c}\text { Between the development } \\
\text { measurements and the canonical } \\
\text { Variables of the Sectoral GDP Share }\end{array}$} & \multicolumn{3}{c}{$\begin{array}{c}\text { Between the Development } \\
\text { Measurements and their } \\
\text { Canonical Variables }\end{array}$} \\
\hline 1994-96 & V1 & V2 & V3 & W1 & W2 & W3 \\
\hline lexp & 0.29 & 0.12 & -0.49 & 0.31 & 0.16 & -0.82 \\
lfdi & -0.15 & 0.17 & -0.26 & -0.16 & 0.22 & -0.44 \\
lgcf & 0.74 & 0.34 & 0.08 & 0.79 & 0.44 & 0.133 \\
lman_vad & 0.55 & 0.31 & -0.00 & 0.57 & 0.40 & -0.00 \\
lemp_prod & 0.83 & -0.25 & -0.09 & 0.87 & -0.32 & -0.15 \\
llife_ex & 0.64 & -0.23 & -0.12 & 0.67 & -0.30 & -0.20 \\
lupp & 0.58 & -0.09 & -0.21 & 0.61 & -0.13 & -0.35 \\
lhepu & 0.30 & 0.03 & 0.02 & 0.31 & 0.04 & 0.03 \\
lind_emp & 0.75 & 0.18 & -0.04 & 0.79 & 0.22 & -0.06 \\
lser_emp & 0.67 & -0.23 & -0.10 & 0.71 & -0.31 & -0.16 \\
2014-16 & & & & & & \\
lexp & 0.46 & 0.08 & -0.28 & 0.48 & 0.12 & -0.48 \\
lfdi & 0.11 & 0.07 & -0.17 & 0.11 & 0.10 & -0.29 \\
lgcf & 0.12 & 0.40 & -0.04 & 0.12 & 0.58 & -0.08 \\
lman_vad & 0.42 & 0.23 & 0.38 & 0.44 & 0.34 & 0.65 \\
lemp_prod & 0.88 & 0.01 & -0.04 & 0.92 & 0.01 & -0.07 \\
llife_ex & 0.68 & -0.31 & -0.09 & 0.71 & -0.45 & -0.16 \\
lupp & 0.78 & -0.07 & 0.05 & 0.80 & -0.10 & 0.09 \\
lhepu & 0.30 & -0.38 & 0.06 & 0.31 & -0.55 & 0.09 \\
lind_emp & 0.34 & 0.05 & 0.23 & 0.35 & 0.07 & 0.39 \\
lser_emp & 0.80 & -0.19 & 0.02 & 0.83 & -0.28 & 0.03 \\
\hline & & & & & &
\end{tabular}

Table 11. Regression estimates for percentage share of value added in agriculture.

(a)

\begin{tabular}{cccccccc}
\hline & \multicolumn{3}{c}{$1994-96$} & & \multicolumn{3}{c}{$2014-16$} \\
\hline Variable & DF & $\begin{array}{c}\text { Parameter } \\
\text { Estimate }\end{array}$ & $\mathbf{t}$ Value & $\operatorname{Pr}>|\mathbf{t}| \begin{array}{c}\text { Parameter } \\
\text { Estimate }\end{array}$ & $\mathbf{t}$ Value & $\operatorname{Pr}>|\mathbf{t}|$ \\
\hline Intercept & 1 & 27.73 & 3.48 & 0.00 & 42.17 & 3.29 & 0.0031 \\
lexp & 1 & -0.19 & -0.83 & 0.41 & -0.22 & -1.01 & 0.3220 \\
lgcf & 1 & -0.09 & -0.20 & 0.84 & 0.38 & 0.74 & 0.4639 \\
lemp_prod & 1 & -0.80 & -3.60 & 0.00 & -0.84 & -2.84 & 0.0091 \\
llife_ex & 1 & -4.23 & -1.98 & 0.05 & -7.67 & -2.36 & 0.0265 \\
lupp & 1 & 0.35 & 0.79 & 0.43 & 0.16 & 0.29 & 0.7738 \\
lhepu & 1 & 0.01 & 0.04 & 0.97 & 0.28 & 0.96 & 0.3463 \\
\hline
\end{tabular}

(b)

\begin{tabular}{ccc}
\hline & $\mathbf{1 9 9 4 - 9 6}$ & $\mathbf{2 0 1 4 - 1 6}$ \\
\hline Root MSE & 0.72 & 0.75 \\
Dependent Mean & 2.74 & 2.13 \\
Coeff Var & 26.25 & 35.50 \\
R-Square & 0.73 & 0.73 \\
Adj R-Sq & 0.66 & 0.67 \\
F Value & 10.35 & 10.82 \\
Pr $>$ F & $<0.00$ & $<0.00$ \\
\hline
\end{tabular}


Regression results for percentage share of value added in industry shows that gross capital formation was a significant determinant for the change in the share of industry for both periods. However, the growth of manufacturing also found to be significant for $2014-16$. The model could explain $50 \%$ variation in the share of industry (Table 12).

Regression results for the percentage share of services shows that improvement in life expectancy was a significant positive determinant of expansion of services sector for 2014-16. The model could explain $24 \%$ variation in the percentage share of services. However, no variables were found to be significant for 1994-96 (Table 13).

\section{Conclusions}

For 1994-96, gross capital formation and life expectancy emerged to be significant positive determinants of structural change in GDP. Growth of manufacturing, employee productivity and employment in services were also significant determinants of structural changes in GDP for 1994-96. For 2014-16, improvement in life expectancy, growth of employee productivity, growth of value added in manufacturing, growth of employment in services and gross capital formation were significant positive determinants of structural change in GDP. However, for 2014-16, the impact of growth of industrial employment was negative on the structural change in GDP share.

Univariate regression results show that the most important factors responsible for the transformation of agriculture are the growth in employee productivity

Table 12. Regression estimates for percentage share of value added in industry.

(a)

\begin{tabular}{cccccccc}
\hline & \multicolumn{3}{c}{$1994-96$} & & \multicolumn{3}{c}{$2014-16$} \\
\hline Variable & DF & $\begin{array}{c}\text { Parameter } \\
\text { Estimate }\end{array}$ & $\mathrm{t}$ Value & $\operatorname{Pr}>|\mathrm{t}|$ & $\begin{array}{c}\text { Parameter } \\
\text { Estimate }\end{array}$ & $\mathrm{t}$ Value & $\operatorname{Pr}>|\mathrm{t}|$ \\
\hline Intercept & 1 & 0.83 & 1.94 & 0.06 & 0.21 & 0.23 & 0.82 \\
lgcf & 1 & 0.65 & 4.72 & 0.00 & 0.43 & 2.05 & 0.05 \\
lman_vad & 1 & -0.01 & -0.10 & 0.92 & 0.44 & 4.75 & 0.00 \\
lemp_prod & 1 & -0.05 & -0.88 & 0.38 & 0.10 & 0.84 & 0.40 \\
lupp & 1 & 0.20 & 1.75 & 0.09 & -0.03 & -0.12 & 0.90 \\
lind_emp & 1 & 0.12 & 0.96 & 0.34 & -0.11 & -0.54 & 0.59 \\
\hline
\end{tabular}

(b)

\begin{tabular}{ccc}
\hline & $\mathbf{1 9 9 4 - 9 6}$ & $\mathbf{2 0 1 4 - 1 6}$ \\
\hline Root MSE & 0.16 & 0.31 \\
Dependent Mean & 3.48 & 3.40 \\
Coeff Var & 4.53 & 9.27 \\
R-Square & 0.80 & 0.58 \\
Adj R-Sq & 0.75 & 0.50 \\
F Value & 17.08 & 6.92 \\
Pr > F & $<0.00$ & $<0.00$ \\
\hline
\end{tabular}


Table 13. Regression estimates for percentage value added in services.

(a)

\begin{tabular}{cccccccc}
\hline & \multicolumn{3}{c}{$1994-96$} & & \multicolumn{3}{c}{$2014-16$} \\
\hline Variable & DF & $\begin{array}{c}\text { Parameter } \\
\text { Estimate }\end{array}$ & $\mathbf{t}$ Value & $\operatorname{Pr}>|t|$ & $\begin{array}{c}\text { Parameter } \\
\text { Estimate }\end{array}$ & $t$ Value & $\operatorname{Pr}>|t|$ \\
\hline Intercept & 1 & -0.55 & -0.22 & 0.83 & -5.00 & -1.78 & 0.08 \\
lemp_prod & 1 & 0.12 & 1.57 & 0.13 & -0.11 & -1.32 & 0.19 \\
llife_ex & 1 & 0.78 & 1.15 & 0.26 & 2.15 & 2.92 & 0.00 \\
lser_emp & 1 & 0.30 & 1.06 & 0.30 & 0.18 & 0.97 & 0.33 \\
lupp & 1 & -0.32 & -1.91 & 0.07 & 0.05 & 0.35 & 0.73 \\
\hline
\end{tabular}

(b)

\begin{tabular}{ccc}
\hline & $\mathbf{1 9 9 4 - 9 6}$ & $\mathbf{2 0 1 4 - 1 6}$ \\
\hline Root MSE & 0.23 & 0.20 \\
Dependent Mean & 3.75 & 3.97 \\
Coeff Var & 6.21 & 5.20 \\
R-Square & 0.40 & 0.34 \\
Adj R-Sq & 0.30 & 0.24 \\
F Value & 3.93 & 3.63 \\
Pr > F & 0.01 & 0.01 \\
\hline
\end{tabular}

and increase in life expectancy which transferred more workforce from agriculture to services. It is notable that improvement in life expectancy was the most important factor responsible for the growth of services sector. Growth of gross capital formation and growth of manufacturing are the most driving factors for the growth of industrial sector.

In order to reduce the contribution of agriculture to GDP and increase the share of non-agricultural sector to GDP, especially, for countries such as Nepal, Cambodia, Myanmar, Tajikistan, Pakistan and Afghanistan, policies to increase life expectancy, employee productivity, employment in services sector, size of manufacturing and gross capita formation are required.

\section{References}

[1] Kuznets, S. (1971) Economic Growth of Nations, Total Output and Productive Structure. Harvard University Press, Cambridge. https://doi.org/10.4159/harvard.9780674493490

[2] Rostow, W.W. (1971) The Stages of Economic Growth. Cambridge University Press, Cambridge.

[3] Chenery, H. and Syrquin, M. (1975) Patterns of Development 1950-70. Oxford University Press, Oxford.

[4] Baumol, W.J., Blackman, S.A.B. and Wolf, E.N. (1989) Productivity and American Leadership. MIT Press, Cambridge.

[5] Echevarria, C. (1997) Changes in Sectoral Composition Associated with Economic Growth. International Economic Review, 38, No. 2. https://doi.org/10.2307/2527382

[6] https://www.scribd.com/doc/33695739/The-Lewis-Theory-of-Development

[7] Sormeaux, A. and Pemberton, C. (2017) Factors Influencing Agriculture's Contri- 
bution to GDP: Latin America and the Caribbean.

[8] Lewis, W.A. (1954) Economic Development with Unlimited Supplies of Labor. The Manchester School, 22, 139-191. https://doi.org/10.1111/j.1467-9957.1954.tb00021.x

[9] Kaldor, N. (1967) Strategic Factors in Economic Development. New York State School of Industrial and Labour Relations, Cornel I University, Ithaca, 7-9.

[10] Cornwall, J. (1977) Modern Capitalism: Its Growth and Transformation. London, Martin Robertson.

[11] Chenery, H.B. (1988) Industrialization and Growth: Alternative Views of East Asia. In: Hughes, H., Ed., Achieving Industrialization in East Asia, New York, Cambridge University Press, Cambridge, 56.

[12] Wu, Y.R. Service Sector Growth in China and India: A Comparison. https://ecompapers.biz.uwa.edu.au/paper/PDF\%20of\%20Discussion\%20Papers/200 7/07_04_Wu.pdf

[13] Mulder, N. (2001) The Economic Performance of the Service Sector in Brazil, Mexico and the United States. In: Stern, R.M., Services in the International Economy, Chapter 8, The University of Michigan Press, Ann Arbor, 185-210.

[14] Wolfl, A. (2005) The Service Economy in OECD Countries in Enhancing the Performance of the Service Sector. OECD, Paris. https://doi.org/10.1787/212257000720

[15] Bhagwati, J. (1984) Splintering and Disembodiment of Services and Developing Nations. World Economy, 7, 133-143. https://doi.org/10.1111/j.1467-9701.1984.tb00265.x

[16] Manly, F.J. (2005) Multivariate Statistical Methods: A Primer. 3rd Edition, Chapman \& HALL/CRC, New York, 91-104. 